\title{
IMPROVEMENT PRODUKSI CRUSHER DENGAN METODE DOUBLE DUMP CRUSHER FC01 DAN FC02 PT. MIFA BERSAUDARA
}

\author{
Ali $^{1)}$, Mohd Prieska ${ }^{1)}$ \\ ${ }^{1)}$ Departemen Mine Operation, PT. Mifa Bersaudara.
}

\begin{abstract}
ABSTRAK
PT. Mifa Bersaudara sesuai dengan rencana produksi pada tahun 2018 akan melakukan coal sales sebesar 5 Juta Ton. Dengan target sales yang besar tentunya di butuhkan support yang besar dari unit-unit produksi. Maka dari itu unit operasional coal getting yang menggunakan OHT pada tahun 2017 diganti menjadi 30T class dengan jumlah yang lebih banyak. Akibat peningkatan produksi pada tahun 2018, perlu dilakukan improvement pada crusher FC01 dan FC02. Crusher FC01 dengan kapasitas produksi 750 tph dengan actual average year to date pada tahun 2017 hanya sebesar 342 tph dan FC02 dengan kapasitas produksi 450 tph dengan actual year to date hanya sebesar 350 tph. Ada beberapa parameter yang mempengarui productivity crusher FC01 dan FC02 yang tidak tercapai, yaitu feeding batubara yang masih kurang dan jarak waktu dumping antar hauler yang masih besar. Untuk meningkatkan productivity crusher FC01 dan crusher FC02 perlu dilakukan re-engineering pada area hopper agar dapat menerima feeding yang lebih besar dan perbaikan area manuver agar dapat diterapkan metode double dump. Langkah yang diambil yaitu dengan penambahan wings pada area hopper crusher $\mathrm{FC} 01$ dan penambahan stopper pada hopper crusher $\mathrm{FC} 02$ agar dapat dilakukan teknik double dump untuk meningkatkan productivity masingmasing crusher. Hasil dari project ini yaitu adanya perubahan area manuver di area dumping hopper FC01 dan FC02 yang menghabiskan biaya sebesar Rp196.215.000,00 dan terdapat perbaikan pada area hopper FC01 dengan menambahkan wings pada sisi kiri dan kanan hopper serta penambahan stopper pada area hopper $\mathrm{FC} 02$ yang menghabiskan biaya sebesar Rp166.140.000,00 dengan total keseluruhan biaya sebesar Rp362.355.000,00. Setelah diterapkan metode double dump pada crusher FC01 dan FC02, productivity crusher FC01 meningkat menjadi 500 tph dan FC02 meningkat menjadi 354 tph dengan total proyeksi revenue yang didapat pada akhir tahun 2018 sebesar \$36,672,864.
\end{abstract}

Kata kunci : crusher, double dump, productivity, cost

\begin{abstract}
PT. Mifa Bersaudara in 2018 planned to conduct 5 million tons of coal sales. With a large sales target, a good support from the production units is a must. Therefore, the coal getting operation that used to utilize Off High Way Trucks (OHT) in 2017 replaced those units with 30 T class trucks with more units. As a result of increased production plan in 2018, improvements for the FCO1 and FCO2 crushers need to be done. FCO1 crusher has a production capacity of 750 tph with an actual year to date in 2017 averaged in 342 tph. FCO2 with a production capacity of 450 tph with an actual year to date figure averaged in 350 tph. There are several parameters that affect the productivity of the $\mathrm{FCO1}$ and $\mathrm{FCO} 2$ crushers. Some of the parameters have not been achieved, such as the lack of coal feeding and long-time dumping intervals between each hauler. In order to increase the productivity of FCO1 crushers and FCO2 crushers it is necessary to re-engineer the hopper area so that it can receive greater feeding and improve the maneuver area to apply double dump technique. The next step was to re-engineer the hopper with the addition of wings to the FC01 crusher's hopper area and addition of stopper to the FCO2 crusher's hopper so that a double dump technique can be used to increase the productivity of each crusher. The results of maneuver area improvement are the wider maneuvering dumping area in the FCO1 and FCO2. This stage costs Rp196.215.000,00. The second stage which is the addition of wings on the left and right sides of the hopper and adding stopper in the FCO2 hopper area costs Rp166.140.000,00 and the total of
\end{abstract}


costs Rp362.355.000,00 . After the double dump method was applied to the FC01 and FC02 crushers, the FCO1 crusher productivity increased to 500 tph and FCO2 increased to 354 tph with a total revenue projection obtained at the end of 2018 of $\$ 36,672,864$.

Keyword : crusher, double dump, productivity, cost

\section{A. PENDAHULUAN}

\section{A.1. Latar Belakang}

PT. Mifa Bersaudara sesuai dengan rencana pada tahun 2018 akan melakukan sales sebesar 3.7 juta ton dan berpeluang akan ramp up produksi hingga 5 juta ton. Dengan target coal sales yang besar tentunya dibutuhkan support yang besar dari unit-unit produksi, yaitu salah satunya dengan memaksimalkan produktivitas crusher. Pada tahun 2017 terdapat perubahan plan fleet coal getting dari OHT 775 dengan kapasitas 35 ton menjadi truck Iveco dengan kapasitas 25 ton. Dengan cycle time yang sama maka dibutuhkan penambahan fleet coal getting untuk meningkatkan produksi serta perlu dilakukan improvement pada crusher FC01 dan FC02 agar dapat mengimbangi produksi coal getting. Crusher FC01 dengan kapasitas produksi 750 tph dengan actual average year to date pada tahun 2017 sebesar 342 tph dan FC02 dengan kapasitas produksi 450 dengan actual year to date pada tahun 2018 sebesar 350 tph. Ada beberapa parameter yang mempengaruhi produktivitas crusher FC01 dan FC02 yang tidak tercapai, yaitu feeding batubara yang masih kurang dan jarak waktu dumping antar hauler yang masih besar. Untuk meningkatkan produktivitas crusher FC01 menjadi 750 tph dan FC02 menjadi 450 tph perlu dilakukan re-engineering pada area hopper agar dapat menerima feeding yang lebih besar dan perbaikan area manuver agar dua hauler dapat melakukan dumping secara bersamaan (double dump) sehingga tidak ada antrian dumping di hopper crusher FC01 dan FC02. Perbaikan area hopper dilakukan dengan memperlebar tampungan hopper dump pada FC01 dan penambahan stopper pada FC02 serta perbaikan area manuver pada masing-masing area dump hopper sehingga dapat dilakukan teknik double dump yang bertujuan untuk meningkatkan produktivitas masing-masing crusher FC01 dan FC02. Peningkatan produktivitas crusher FC01 di angka optimal hingga 750 tph dan crusher FC02 di angka optimal 450 tph bertujuan untuk mencapai produksi 5 juta ton dengan potensial revenue pada tahun 2018 senilai 36 juta dollar.

\section{A.2. Rumusan Masalah}

1) Apa yang menyebabkan kapasitas produksi crusher FC01 dan FC02 tidak tercapai?

2) Bagaimana langkah untuk mencapai kapasitas produksi crusher FC01 dan FC02?

3) Bagaimana hasil produktivitas setelah dilakukan improvement pada cruser FC01 dan FC02?

4) Berapa proyeksi keuntungan yang didapatkan setelah dilakukan improvement?

\section{A.3. Tujuan Penelitian}

Penelitian ini bertujuan untuk mengkaji teknis penerapan double dump untuk memaksimalkan produktivitas crusher FC01 dari 342 tph menjadi 750 tph dan crusher FC02 dari 350 tph menjadi 450 tph serta mengkaji keuntungan yang akan didapatkan setelah crusher dilakukan perbaikan.

\section{B. TINJAUAN PUSTAKA}

\section{B.1. Coal Crushing Plant (CCP)}

Coal crushing plant merupakan bagian dari operasional penambangan batubara yang menjadi tempat pengolahan batubara dari tambang agar menjadi produk yang siap untuk dijual. Coal crushing plant merupakan rangkaian peralatan mekanis yang digunakan untuk mereduksi ukuran hasil penambangan. Pengolahan batubara hasil penambangan perlu dilakukan pengecilan ukuran 
terutama untuk memenuhi atau menyesuaikan dengan permintaan konsumen akan kualitas dan ukuran butiran (Imam dkk., 2017). Batubara yang berasal dari tambang di angkut ke Coal Crushing Plant dengan menggunakan dump truck Iveco berkapasitas 25 ton. Batubara yang diangkut akan di umpankan ke dalam hopper baik pada crusher FC01 maupun FC02. Berdasarkan desain dan kapasitas produksi, crusher FC01 memiliki kapasitas produksi mencapai 750 ton per jam sedangkan crusher FC02 memiliki kapasitas produksi mencapai 450 ton per jam.

\section{B.2. Produktivitas Crusher}

Produktivitas crusher merupakan total produksi crusher dalam satu jam. Produktivitas crusher merupakan jumlah tonase batubara yang dumping pada hopper dalam setiap jam selama crusher beroperasi. Produktivitas crusher ini sangat berkaitan dengan jumlah hauler yang melakukan dumping pada hopper baik di crusher FC01 maupun crusher FC02. Pada tahun 2017 aktivitas coal getting dilakukan dengan menggunakan unit OHT 775 dan OHT 773 dengan masing-masing kapasitasnya 35 ton dan 31 ton dengan produktivitas year to date crusher FC01 sebesar 342 tph dan FC02 sebesar 350 tph. Dengan peningkatan produksi pada tahun 2018, unit OHT diganti dengan unit Iveco dengan kapasitas 25 ton. Dengan kapasitas hauler yang lebih sedikit, maka fleet coal getting mengalami penambahan unit agar target produksi tahun 2018 tercapai yaitu 3,7 juta ton dan akan ramp up menjadi 5 juta ton.

Berdasarkan year to date produktivitas crusher FC01 pada tahun 2017 sebelum dilakukan improvement sebesar 342 dan diharapkan akan bisa mencapai 750 sesuai dengan kapasitas produksinya. Sementara itu, year to date produktivitas crusher FC02 mulai bulan Januari hingga September 2018 sebelum dilakukan improvement sebesar 350 tph dan diharapkan akan meningkat menjadi 450 sesuai dengan kapasitas produksi crusher FC02.

Tabel 1 Produktivitas Crusher FC01 tahun 2017 sebelum dilakukan improvement

\begin{tabular}{ccc}
\hline Bulan & Produktivitas & Rata-rata \\
\hline Januari & 323.0 & 342.35 \\
Februari & 355.7 & 342.35 \\
Maret & 343.9 & 342.35 \\
April & 367.5 & 342.35 \\
Mei & 343.7 & 342.35 \\
Juni & 339.4 & 342.35 \\
Juli & 335.7 & 342.35 \\
Agustus & 343.4 & 342.35 \\
September & 268 & 342.35 \\
Oktober & 340 & 342.35 \\
November & 361 & 342.35 \\
Desember & 387 & 342.35 \\
\hline
\end{tabular}

Sumber : Data Produksi Tahunan PT. Mifa Bersaudara

Tabel 2 Produktivitas Crusher FC02 tahun 2018 sebelum dilakukan improvement

\begin{tabular}{ccc}
\hline Bulan & Produktivitas & Rata-rata \\
\hline Januari & 389 & 350 \\
Februari & 304 & 350 \\
Maret & 337 & 350 \\
April & 359 & 350 \\
Mei & 355 & 350 \\
Juni & 365 & 350 \\
Juli & 359 & 350 \\
Agustus & 318 & 350 \\
September & 362 & 350 \\
\hline
\end{tabular}

Sumber : Data Produksi Tahunan PT. Mifa Bersaudara 


\section{METODOLOGI PENELITIAN}

\section{C.1. Project Identification}

Tahap awal dari pengerjaan project ini yaitu dengan melakukan identifikasi unutk mengetahui penyebab-penyebab tidak tercapainya produktivitas pada crusher FC01 dan FC02 untuk ditemukan solusi alternatif. Melalui pengumpulan data coal crushing pada saat sebelum dilakukan improvement pada masing-masing crusher.

\section{C.2. Project Initiation}

Pada tahap ini dilakukan analisa terhadap data actual crushing, productivity, performa crusher, dan design hopper crusher FC01 dan FC02 untuk menemukan titik permasalahan dan dapat ditentukan solusi yang terbaik.

\section{C.3. Project Planning}

Setelah data didapatkan dan di analisa serta didapatkan alternatif solusi, maka tahap selanjutnya yaitu merencanakan perbaikan yang akan dilakukan dan menyusun timeline pengerjaan project.

\section{C.4. Project Execution}

Project ini dimulai pada bulan Januari 2018 untuk perbaikan FC01 dan pada bulan September 2018 untuk perbaikan FC02. Selain sesuai dengan plan untuk meningkatkan produksi secara bertahap, hal ini dilakukan agar kegiatan crushing di PT. Mifa Bersaudara tetap dapat berjalan. Adapun perbaikan yang dilakukan untuk meningkatkan produktivitas crusher FC01 dan FC02 yaitu dengan dua langkah, yaitu:

1) Extend Hopper FC01 dengan penambahan wing pada sisi kanan dan kiri hopper FC01 dan penambahan stopper pada $\mathrm{FC} 02$.

2) Re-design area manuver agar lebih luas sehingga dapat diterapkan teknik double dump pada crusher FC01 dan FC02.

\section{C.5. Project Monitoring}

Setelah selesai dilakukan perbaikan pada masing-masing crusher, maka dilakukan monitoring terhadap produktivitas crusher. Monitoring produktivitas crusher FC01 dimulai pada bulan Januari - Desember 2018 dan pada FC02 dimulai pada bulan September - Desember 2018. Hasil akhir yang didapatkan yaitu keuntungan dari peningkatan produktivitas setelah dilakukan improvement pada masing-masing crusher.

\section{HASIL DAN PEMBAHASAN}

\section{D.1. Improvement crusher FC01 dan FC02}

\section{a. Extend hopper FC01 dan FC02}

Ada beberapa hal yang mempengaruhi produktivitas crusher antara lain adalah feeding dari batubara. Dimana total feeding merupakan jumlah dari produksi crusher. Sehingga makin besar feeding pada hopper FC01 dan FC02 maka produktivitas crusher akan semakin besar. Dengan extend hopper dump pada crusher FC01 dan FC02 diharapkan dapat meningkatkan jumlah feeding terhadap FC01 dan FC02 sehingga produktivitas crusher FC01 dan FC02 akan meningkat. Extend hopper FC01 dilakukan dengan menambahkan sayap (wings) pada sisi kiri dan kanan hopper FC01. Wings ini berfungsi untuk memperluas tampungan hopper di FC01. 


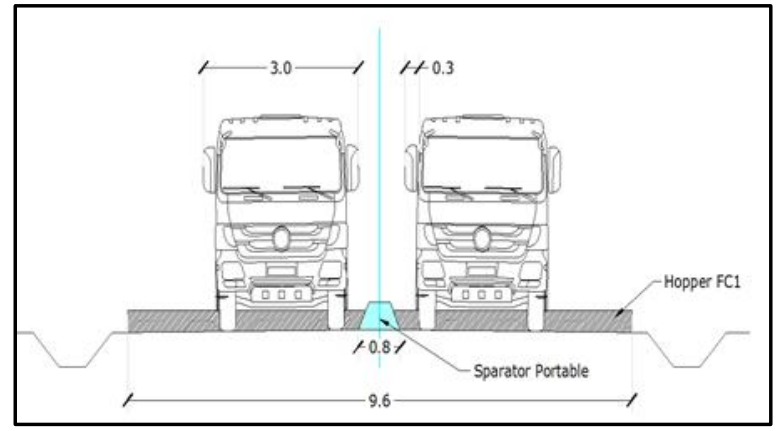

Gambar 1 Desain double dump FC01
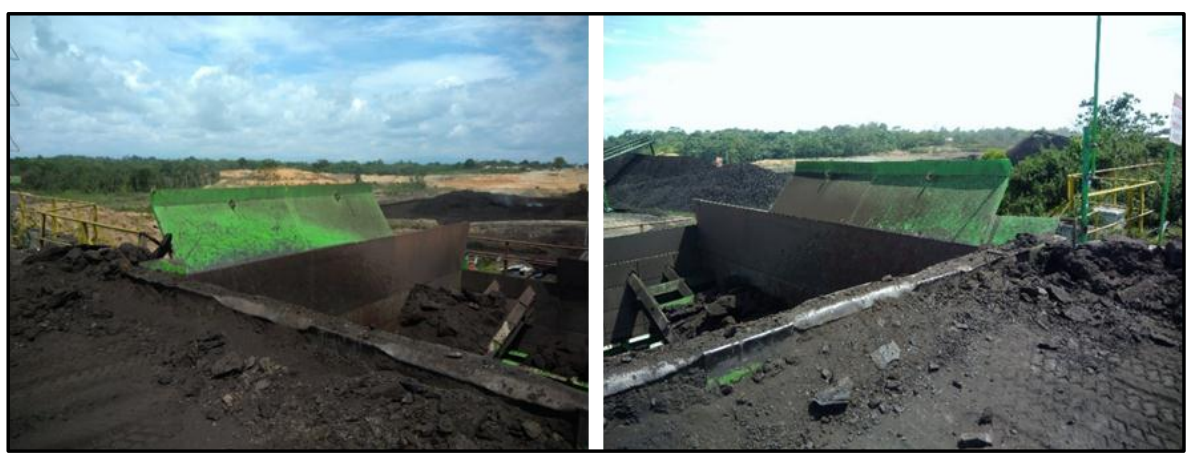

Gambar 2 Extend hopper FC01 dengan penambahan wings

Awal dibangun FC02 memiliki hopper yang digunakan untuk menampung coal feeding dengan metode single dump, namun dimensi persegi hopper yang berukuran 6 meter x 7 meter memiliki peluang untuk dilakukan metode double dump (lihat gambar) sehingga dilakukan perbaikan di area hopper FC02 dengan menambah stopper dan pad dump untuk menunjang aktivitas double dump dapat berjalan dengan aman.

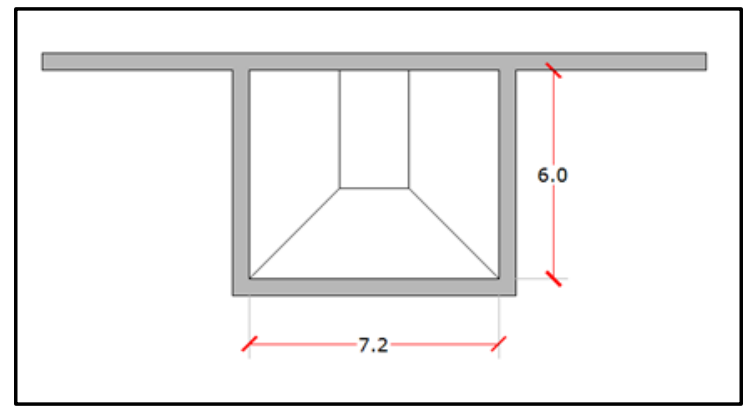

Gambar 3 Desain double dump FC02

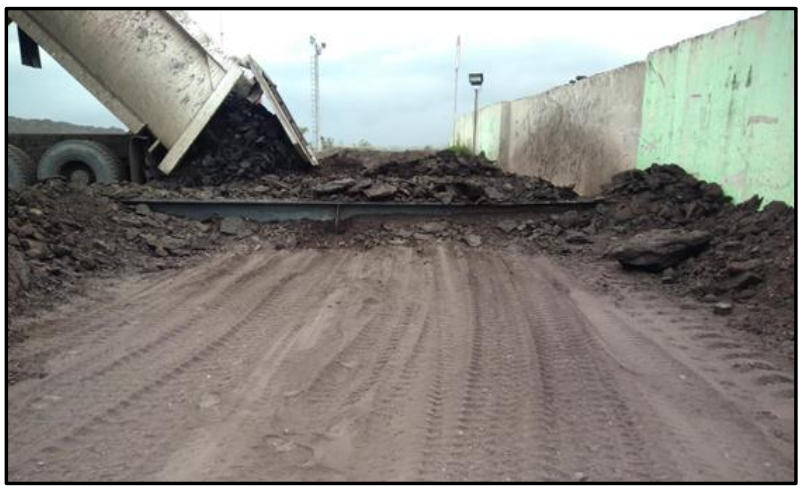

Gambar 4. Penambahan stopper pada sisi selatan FC02 
Alat dan bahan yang digunakan untuk perbaikan tersebut secara rinci terdiri dari H-beam, pad beton dan plat besi serta alat-alat support untuk mengerjakan pekerjaan tersebut.

Tabel 3. Biaya extend hopper FC01

\begin{tabular}{|c|c|c|c|c|c|}
\hline No. & Material & $\bar{Q}$ & Unit & Estimasi harga & Total harga \\
\hline 1 & UNP 150 & 6 & Batang & Rp. 780.000 & Rp. 4.680 .000 \\
\hline 2 & Plat $10 \mathrm{~mm}$ & 4 & Lembar & Rp. 1.731 .000 & Rp. 6.924 .000 \\
\hline 3 & Boarder greating & 2 & Lembar & Rp. 733.000 & Rp. 1.466 .000 \\
\hline 4 & Besi siku 50/50 & 6 & Batang & Rp. 180.000 & Rp. 1.080 .000 \\
\hline \multirow[t]{2}{*}{5} & Road barrier/separator & 6 & Set & Rp. 780.000 & Rp. 4.680 .000 \\
\hline & & & & Tota & Rp. 18.830 .000 \\
\hline
\end{tabular}

Tabel 4. Biaya extend hopper FC02

\begin{tabular}{|c|c|c|c|c|c|}
\hline No. & Material & Q & Unit & Estimasi harga & Total harga \\
\hline 1 & Pad beton & 3 & Lembar & Rp. 26.000.000 & Rp. 26.000 .000 \\
\hline 2 & H-beam & 1 & Batang & Rp. 0 & Rp. 0 \\
\hline 3 & Boarder greating & 2 & Lembar & Rp. 0 & Rp. 0 \\
\hline
\end{tabular}

\section{b. Re-Design manuver area dumping hopper FC01 dan FC02}

Seiring dengan peningkatan target produksi pada tahun 2018 maka perlu adanya penambahan fleet coal getting agar target produksi tercapai. Dengan cycle time yang sama dengan jumlah hauler yang bertambah akan menyebabkan antrian dumping pada hopper FC01 dan FC02. Maka dari itu, selain perbaikan pada hopper maka perlu dilakukan perbaikan pada area manuver agar teknik double dump diterapkan dengan baik. Perubahan desain manuver ini meliputi perluasan area manuver disekitar hopper dan pembuatan pavement jalan agar area manuver dumping tidak mudah rusak akibat sering dilalui oleh hauler yang bermuatan. Pavement jalan meliputi lapisan tanah dasar, lapisan sub base coarse (lapisan batu mangga) dan lapisan base coarse sirtu (lapisan gravel dan sand).

\begin{tabular}{|c|c|c|c|}
\hline Sub-base & 785 & 8 & t2 \\
\hline $\mathrm{t} 1$ & $\begin{array}{l}\text { River rock } \\
\text { spesific matrl: } \\
\text { Rriver rock size min } 3.5 \text { inch }(8 \mathrm{~cm}) \\
\text { number of layer } \\
\text { thich each layer }\end{array}$ & $\begin{array}{r}2 \\
7.0\end{array}$ & $\mathrm{~cm}$ \\
\hline t2 & $\begin{array}{l}\text { Gravel+sand } \\
\text { spesific matrl : } \\
\text { Gravel + Sand (garvel } 70 \%+\text { Sand } 30 \% \text { ) } \\
\text { number of layer } \\
\text { thich each layer }\end{array}$ & $\begin{array}{r}1 \\
33.6\end{array}$ & $\mathrm{~cm}$ \\
\hline
\end{tabular}

Gambar 5. Desain pavement untuk area manuver di FC01 dan FC02

Sub base batu mangga yang dibutuhkan sebanyak $321 \mathrm{~m}^{3}$ dan base coarse sirtu yang dibutuhkan adalah sebanyak $1251 \mathrm{~m}^{3}$ dengan biaya yang dikeluarkan sebesar Rp.196.215.000. Alat yang digunakan untuk pembuatan pavement jalan ini yaitu, 1 unit excavator, 1 unit grader, 1 unit compactor dan 2 unit DT dengan biaya yang dikeluarkan sebesar Rp. 166.140.000. 
Tabel 5. Biaya pavement construction FC01

\begin{tabular}{clcl}
\hline No. & \multicolumn{1}{c}{ Pavement Construction FC01 } & Jumlah $\left(\mathrm{m}^{3}\right)$ & \multicolumn{1}{c}{ Biaya } \\
\hline 1 & Sub Base Coarse Mangga & 296 & Rp. 79.920.000 \\
2 & Base Coarse Sirtu & 1221 & Rp. 106.920.000 \\
\hline & & Total & Rp. 186.840.000 \\
\hline
\end{tabular}

Tabel 6. Biaya pavement construction $\mathrm{FC} 02$

\begin{tabular}{clcc}
\hline No. & Pavement Construction FC01 & Jumlah $\left(\mathrm{m}^{3}\right)$ & Biaya \\
\hline 1 & Sub Base Coarse Mangga & 25 & Rp. 7.750 .000 \\
2 & Base Coarse Sirtu & 30 & Rp. 2.625.000 \\
\hline & & Total & Rp. 9.375.000 \\
\hline
\end{tabular}

Tabel 7. Biaya penggunaan alat untuk extend hopper FC01

\begin{tabular}{clcccc}
\hline No. & \multicolumn{1}{c}{ Alat yang digunakan } & $\begin{array}{c}\text { Jumlah } \\
\text { unit }\end{array}$ & $\begin{array}{c}\text { Produktivitas } \\
(\mathrm{bcm} / \mathrm{jam})\end{array}$ & Jam Kerja & Biaya \\
\hline 1 & Excavator Zaxis 210 & 1 & 110 & 109 & Rp. 32.700.000 \\
2 & Vibro Compactor Sakai 512 & 1 & 100 & 120 & Rp. 41.400.000 \\
3 & Dump Truck 20 M & & 40 & 150 & Rp. 33.000.000 \\
\hline & & 2 & & Total & Rp. 107.100.000 \\
\hline
\end{tabular}

Tabel 8. Biaya penggunaan alat untuk extend hopper FC02

\begin{tabular}{clcccc}
\hline No. & \multicolumn{1}{c}{ Alat yang digunakan } & $\begin{array}{c}\text { Jumlah } \\
\text { unit }\end{array}$ & $\begin{array}{c}\text { Produktivitas } \\
(\mathrm{bcm} / \mathrm{jam})\end{array}$ & Jam Kerja & Biaya \\
\hline 1 & Excavator Zaxis 210 & 1 & 110 & 36 & Rp. 10.800.000 \\
2 & Vibro Compactor Sakai 512 & 1 & 100 & 120 & Rp. 41.400.000 \\
3 & Dump Truck 20 M & 2 & 40 & 12 & Rp. 4.200.000 \\
4 & Motor Grader Komatsu 511A & 1 & 100 & 12 & Rp. 2.640.000 \\
\hline & & & Total & Rp. 59.040.000 \\
\hline
\end{tabular}

Perubahan desain manuver pada hopper FC01 yaitu dengan meluaskan area manuver ke arah timur, barat dan utara. Sedangkan perbaikan desain manuver pada hopper FC02 yaitu dengan meluaskan area manuver kearah utara dan selatan. Adapun perbaikan desain pada hopper FC01 dan FC02 ditunjukkan melalui gambar dibawah ini:

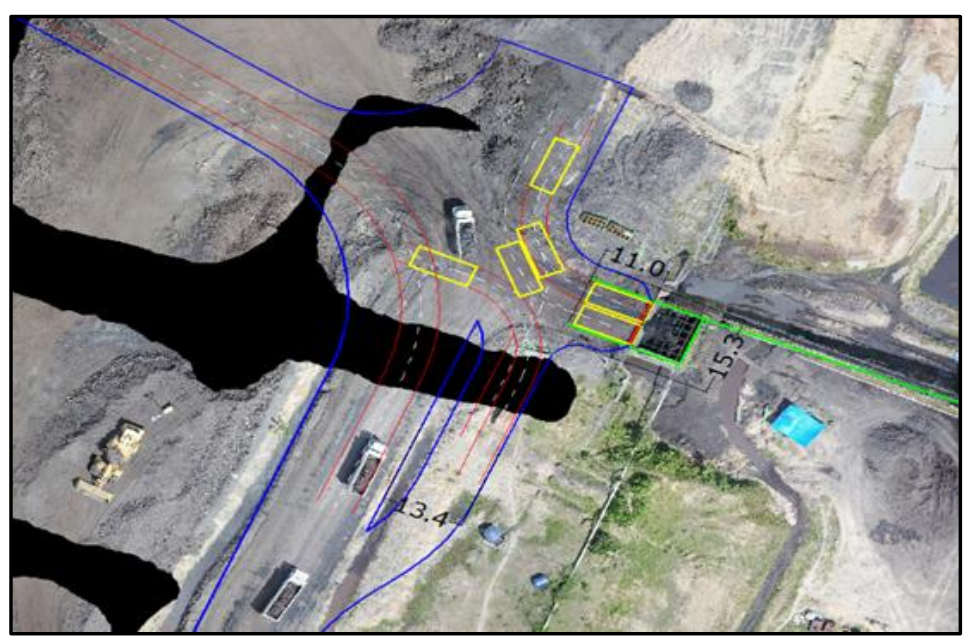

Gambar 6. Desain manuver area pada hopper FC01 


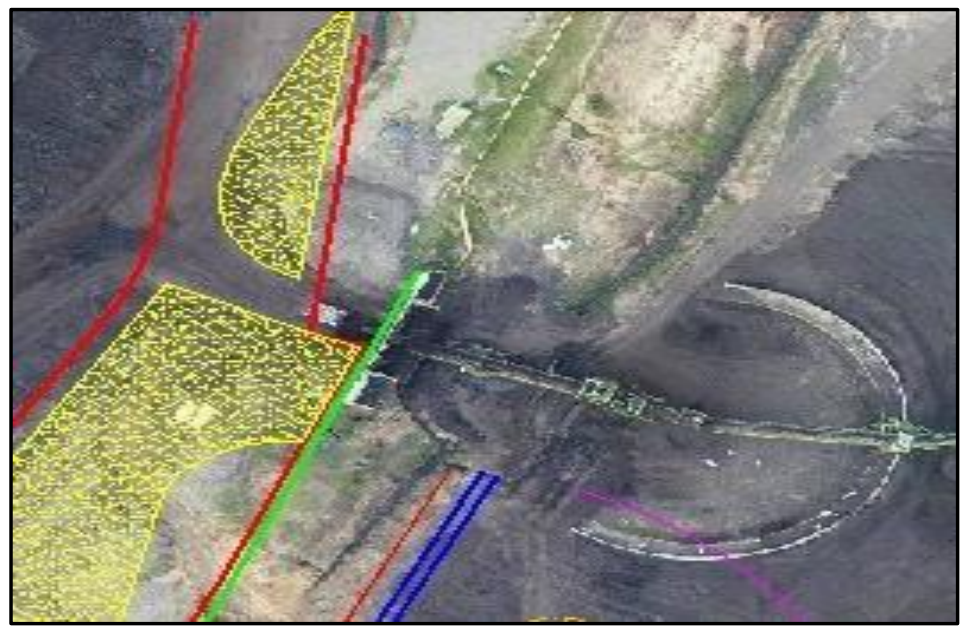

Gambar 7. Desain manuver area pada hopper FC02

\section{D.2. Produktivitas Crusher FC01 dan FC02}

Rata-rata produktivitas crusher FC01 pada tahun 2017 sebesar 342 tph dan setelah dilakukan improvement ditargetkan akan bisa mencapai 750 tph sesuai dengan kapasitas produksinya. Setelah dilakukan perbaikan pada hopper FC01 dengan penambahan wings dan perbaikan area manuver, terdapat peningkatan produktivitas crusher. Double dump pada hopper FC01 efektif dimulai pada bulan Februari tahun 2018. Produktivitas crusher FC01 tahun 2018 mengalami peningkatan dengan rata-rata sebesar 500 tph. Proyeksi revenue yang akan didapatkan sebesar \$ 36 juta. Produktivitas crusher FC01 dapat dilihat melalui tabel 9.

Tabel 9. Produktivitas FC01 setelah dilakukan improvement

\begin{tabular}{lrrrr}
\hline Tahun 2018 & Working hours & $\begin{array}{c}\text { After improvement } \\
\text { (tph) }\end{array}$ & Production & Deviation Production \\
\hline January & 260 & 323.0 & 397.9 & 83989.41359 \\
February & 259 & 355.7 & 472.1 & 92125.99553 \\
March & 322 & 343.9 & 462.8 & 110749.092 \\
April & 291 & 367.5 & 496.1 & 106932.1933 \\
May & 310 & 343.7 & 478.4 & 106532.9571 \\
June & 292 & 339.4 & 551.9 & 99090.39067 \\
July & 269 & 335.7 & 470.2 & 90292.87775 \\
August & 307 & 343.4 & 487.0 & 105434.1744 \\
September & 209 & 267.7 & 549.1 & 55955.01556 \\
October & 446 & 340.0 & 561.2 & 151632.4275 \\
November & 272 & 361.3 & 544.4 & 98269.09817 \\
December & 208 & 386.9 & 537.0 & 80478.70569 \\
& Rata-rata & 500 & Total deviation & 1460226.154 \\
& & & Revenue $(\$ 25 /$ ton $)$ & $\$ 36,505,654$ \\
\hline
\end{tabular}

Setelah beberapa perbaikan untuk peningkatan produksi FC02 diterapkan, dilakukan monitoring terhadap produktivitas FC02 yang sudah menerapkan metode double dump terhitung dari bulan September sampai dengan Desember 2018 dengan hasil seperti tabel dibawah ini : 
Tabel 10. Produktivitas FC02 setelah dilakukan improvement

\begin{tabular}{ccc}
\hline Tahun 2018 & Produktivitas (ton/jam) & Target (ton/jam) \\
\hline September & 374 & 450 \\
Oktober & 344 & 450 \\
November & 361 & 450 \\
Desember & 335 & 450 \\
Rata-rata & 354 & \\
\hline
\end{tabular}

Terdapat peningkatan produktivitas rata-rata dengan selisih produktivitas rata-rata sebelumnya yaitu 4 ton per jam. Keuntungan finansial yang didapat pada tahun 2018 dari hasil perbaikan ini dapat dilihat pada tabel dibawah ini :

Tabel 11. Perhitungan revenue FC02 setelah dilakukan improvement

\begin{tabular}{ccccccc}
\hline & \multicolumn{4}{c}{ Improvement (ton/hour) } & \multicolumn{3}{c}{ Revenue (\$25/ton) } \\
Year 2018 & EWH & Before & After & Before & After & Deviation \\
\hline September & 375.29 & 350 & 354 & $\$ 3.283 .817$ & $\$ 3.321 .346$ & $\$ 37.529$ \\
Oktober & 479.59 & 350 & 354 & $\$ 4.196 .442$ & $\$ 4.244 .401$ & $\$ 47.959$ \\
November & 357.80 & 350 & 354 & $\$ 3.130 .721$ & $\$ 3.166 .501$ & $\$ 35.780$ \\
Desember & 459.42 & 350 & 354 & $\$ 4.019 .925$ & $\$ 4.065 .867$ & $\$ 45.942$ \\
\hline Total & & & & & $\$ 167.210$ \\
\hline
\end{tabular}

Total biaya yang dikeluarkan untuk pengerjaan ini meliputi perbaikan hopper FC01 dan FC02 serta perbaikan area manuver pada hopper FC01 dan FC02 sebesar Rp362,355,000.000. Sedangkan proyeksi revenue yang didapatkan setelah crusher FC01 dan FC02 dilakukan improvement adalah sebesar \$36,672,864 dengan harga batubara untuk kelas sub-bituminous sebesar 25 dollar per ton pada tahun 2018

\section{E. KESIMPULAN}

1) Metode improvement untuk peningkatan produktivitas crusher FC01 dan FC02 dengan dua cara yaitu extend hopper serta perbaikan area manuver dumping pada hopper FC01 dan FC02.

2) Produktivitas year to date FC01 sebesar 342 tph pada tahun 2017 mengalami peningkatan setelah dilakukan improvement dengan rata-rata sebesar 500 tph pada tahun 2018.

3) Produktivitas FC02 sebesar 350 tph year to date dari Januari hingga Agustus dan mengalami peningkatan setelah dilakukan improvement dengan rata-rata sebesar 354 tph mulai September hingga Desember 2018.

4) Biaya yang dikeluarkan untuk improvement crusher FC01 sebesar Rp293.940.000,00 dan improvement crusher FC02 sebesar Rp68.415.000,00, sehingga total keseluruhan biaya adalah Rp362.355.000,00.

5) Proyeksi revenue yang didapat dari improvement FC01 sebesar $\$ \$ 36,505,654$ dan FC02 sebesar $\$ 167,210$, sehingga total proyeksi revenue keseluruhan yang didapat sebesar $\$ 36,672,864$.

\section{DAFTAR PUSTAKA}

Bulo', Ryant. dkk., (2017). Analisis Produktivitas Unit Peremuk Batubara (Crushing Plant) untuk Pencapaian Hasil Produksi di PT. Cms Kaltim Utama Kecamatan Samarinda Utara Kota Samarinda Provinsi Kalimantan Timur. Jurnal Teknologi Mineral FT UNMUL. 5(1): 5764.

Gupta, A. And Yan, D.S (2006) Mineral Processing Design and Operations - An Introduction, Perth, Australia. 
Hartman, Howard., (1992). SME Mining Engineering Handbook. Society for mining, metallurgy and exploration, volume 1: second edition.

Imam. dkk., (2017). Evaluasi Crushing Plant Dan Alat Support Untuk Pengoptimalan Hasil Produksi di PT Binuang Mitra Bersama Desa Pualam Sari, Kecamatan Binuang. Jurnal Himasapta. 2(2): 21-26.

Osborne, D.G., (1988). Coal Preparation Technology, BP Coal Ltd, London.

PT Mifa Bersaudara., (2018). Dokumen PT Mifa Bersaudara. PT Mifa Bersaudara, Aceh Barat, Aceh.

Wills, B.A., (1979). Mineral Processing Technology, 1st Edition, Pergamon Press, New York.

Yunisa, Eva., (2010). Evaluasi Kinerja Crushing Plant Dalam Pencapaian Target Produksi Batubara di Bhumi Rantau Energi PT. Kalimantan Prima Persada Site Rantau Desa Sabah, Kec. Bungur, Provinsi Kalimantan Selatan. Skripsi. Jurusan Teknik Pertambangan. Universitas Lambung Mangkurat 